\title{
Comparison of stimulated parotid salivary gland flow rates in normotensive and hypertensive persons
}

\author{
Charles F. Streckfus, DDS, MA, ${ }^{a}$ Ava J. Wu, DDS, ${ }^{b}$ Jonathan A. Ship, DMD, ${ }^{\mathrm{c}}$ and \\ L. Jackson Brown, DDS, PhD, ${ }^{a}$ Bethesda, Md. and Ann Arbor, Mich. \\ NATIONAL INSTITUTES OF HEALTH AND UNIVERSITY OF MICHIGAN SCHOOL OF DENTISTRY
}

\begin{abstract}
Although hypertension is a prevalent condition among the elderly, little is known with respect to the influence of hypertension on oral health and function. Therefore a study was conducted that compared stimulated parotid salivary flow rates in elderly persons ( 65 years and older) from two diverse populations who are normotensive, mild, and severe hypertensive. The normotensive group consisted of 45 healthy subjects with systolic blood pressures of less than $140 \mathrm{~mm} \mathrm{Hg}$ and diastolic pressures less than $90 \mathrm{~mm} \mathrm{Hg}$. The mildly hypertensive group consisted of 14 otherwise healthy subjects with either systolic pressures greater than $140 \mathrm{~mm} \mathrm{Hg}$ or diastolic pressures greater than $90 \mathrm{~mm} \mathrm{Hg}$. The severely hypertensive group consisted of 10 otherwise healthy subjects with either systolic pressures greater than $180 \mathrm{~mm} \mathrm{Hg}$ and/or diastolic pressures greater than $100 \mathrm{~mm} \mathrm{Hg}$. All three groups were not taking any prescription or nonprescription medications. Samples of $2 \%$ citrate-stimulated parotid saliva were collected from each subject. The results showed no significant differences in stimulated parotid flow between normotensive, mildly hypertensive, and severely hypertensive subjects. These results suggest that hypertension per se has no influence on stimulated parotid salivary gland flow rates in otherwise healthy, elderly unmedicated white and African-American persons. (Oral Surg Oral Med Oral Pathol 1994;77:615-9)
\end{abstract}

The production of saliva by the major and minor salivary glands is essential for the maintenance and protection of the hard and soft tissues of the oral cavity and the inhibition of serious systemic pathogens. ${ }^{1}$ In addition, saliva has an important functional role in speech, swallowing, and mastication. ${ }^{2}$

Dryness of the mouth, xerostomia, is usually a common complaint of the elderly especially among persons who are hypertensive. ${ }^{3}$ Several investigators have attributed this symptom to the side effects resulting from the use of antihypertensive medications., ${ }^{4}$ Hydrochlorothiazide, for example, has been shown to decrease stimulated whole saliva and stimulated parotid gland saliva in patients who take medication for the treatment of hypertension. $4,6-8$

Other reports concern the effects of antihypertensive medications on salivary flow; however, there is little information concerning salivary gland function in hypertensive persons before treatment with antihypertensive medications. Ben-Aryeh et al. ${ }^{9}$ reported lower unstimulated whole saliva flow rates in $10 \mathrm{pa}-$ tients with essential hypertension when compared with age and gender matched normotensive controls. Conversely, in a racially mixed population, Nieder-

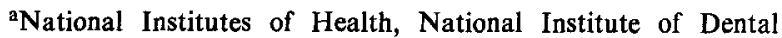
Research, Epidemiology Oral Disease Prevention Program.

${ }^{b}$ National Institutes of Health, National Institute of Dental Research, CIPCB.

'University of Michigan School of Dentistry. Copyright $\odot 1994$ by Mosby-Year Book, Inc. 0030-4220/94/\$3.00 + $0 \quad 7 / \mathbf{1 3} / \mathbf{5 3 5 8 7}$
}

meier et al., ${ }^{10}$ found no differences in unstimulated and stimulated whole salivary flow rates in persons with hypertension when compared with a control group with normal blood pressure. Both studies used whole saliva in their investigations. However, no information is available on the influence of elevated blood pressure on major salivary gland flow rates.

The purpose of this study was to investigate the effects of hypertension on stimulated parotid flow in two different elderly populations, one white and the other African-American.

\section{MATERIAL AND METHODS Populations}

Baltimore Longitudinal Study of Aging. The subjects participating in this study were volunteer participants in the oral physiology component ${ }^{11}$ of the Baltimore Longitudinal Study of Aging (BLSA). ${ }^{12}$ All were community dwelling, ambulatory, elderly (65 years and older) whites of middle socioeconomic class seen by one investigator (J.A.S.). Participants were examined by a physician, and diagnoses of hypertension were based on clinical findings and medical histories. ${ }^{13}$ The normotensive or the hypertensive groups had never used any antihypertensive medications. In addition, they were not taking any prescription or nonprescription medications at the time of evaluation.

Washington Village Medical Center. The subjects participating in this study from the Washington Village Medical Center (WVMC) were African-Americans residing in the southwest section of Baltimore 
Table I. Numbers of subjects, mean blood pressures, and salivary flow rates for study population groups

\begin{tabular}{c|c|c|c|c}
\hline Groups & $n$ & $\begin{array}{c}\text { Systolic } \\
\text { pressure } \\
m m ~ H g\end{array}$ & $\begin{array}{c}\text { Diastolic } \\
\text { pressure } \\
m m ~ H g\end{array}$ & $\begin{array}{c}\text { Stimulated } \\
\text { parotid } \\
\text { flow rate mL/Min }\end{array}$ \\
\hline $\begin{array}{c}\text { BLSA* } \\
\text { normotensives } \\
\text { BLSA }\end{array}$ & 31 & 120 & 67 & 0.59 \\
$\begin{array}{c}\text { hypertensives } \\
\text { (mild) }\end{array}$ & 14 & 139 & 93 & 0.49 \\
$\begin{array}{c}\text { WVMC } \\
\text { normotensives }\end{array}$ & 15 & 129 & 86 & 0.69 \\
$\begin{array}{c}\text { WVMC } \\
\text { hypertensives } \\
\text { (severe) }\end{array}$ & 10 & 167 & 112 & 0.68 \\
$\begin{array}{c}\text { Combined } \\
\text { BLSA and } \\
\text { WVMC }\end{array}$ & 46 & 125 & 76 & 0.62 \\
normotensives & & & \\
\hline
\end{tabular}

${ }^{*}$ Baltimore Longitudinal Study on Aging.

†Washington Village Medical Center.

City, Md. All were ambulatory, geriatric patients (65 years old and older) who were seeking routine medical and dental care at the WVMC, were of a low socioeconomic class, and were seen by one investigator (C.F.S.). Detailed demographic and social characteristics have been reported previously. ${ }^{14}$

The hypertensive persons from the WVMC who were used in this study were asymptomatic persons who were found to have undiagnosed hypertension as a result of routinc hypertension screenings at the dental clinic. Stimulated parotid flow rates were determined before the persons were to initiate their antihypertension therapy. The participants from the WVMC had never taken antihypertensive medications and were not taking any prescription or nonprescription medications at the time of evaluation.

\section{Blood pressure determinations}

Blood pressures were taken between $8 \mathrm{AM}$ and 12 M. with a Baumanometer on the right arm with the patient in a sitting position. The blood pressure values were determined according to the criteria established in the 1993 edition of the Fifth Report of the Joint National Committee on Detection, Evaluation, and Treatment of High Blood Pressure." 15 The categories of blood pressure were also established according to the classifications published in this volume. ${ }^{15}$ The classifications are: normotensive, high normal normotensive, and hypertensive. ${ }^{15}$

Normotension was defined as systolic blood pressure less than $130 \mathrm{~mm} \mathrm{Hg}$ and diastolic pressure less than $90 \mathrm{~mm} \mathrm{Hg}$. High normal hypertensive persons were those with a systolic prcssurc of 130 to $139 \mathrm{~mm}$
$\mathrm{Hg}$ and diastolic pressure less than $90 \mathrm{~mm} \mathrm{Hg}$. The high normotensive were also included in the normotensive group in this study.

Hypertension was classified into four subcategories: mild hypertension, moderate hypertension, severe hypertension, and very severe hypertension.

Mild hypertension was defined as a systolic blood pressure greater than $140 \mathrm{~mm} \mathrm{Hg}$ but less than 159 $\mathrm{mm} \mathrm{Hg}$ and diastolic pressure greater than $90 \mathrm{~mm} \mathrm{Hg}$ but less than $100 \mathrm{~mm} \mathrm{Hg}$. Moderate hypertension was defined as systolic pressure greater than $160 \mathrm{~mm} \mathrm{Hg}$ but less than $179 \mathrm{~mm} \mathrm{Hg}$ and diastolic pressure greater than $100 \mathrm{~mm} \mathrm{Hg}$ but less than $109 \mathrm{~mm} \mathrm{Hg}$. Severe hypertension was defined as systolic pressure greater than $180 \mathrm{~mm} \mathrm{Hg}$ but less than $209 \mathrm{~mm} \mathrm{Hg}$ and diastolic pressure greater than $110 \mathrm{~mm} \mathrm{Hg}$ but less than $119 \mathrm{~mm} \mathrm{Hg}$. Very severe hypertension was defined as systolic pressure greater than $210 \mathrm{~mm} \mathrm{Hg}$ and diastolic pressure greater than $120 \mathrm{~mm} \mathrm{Hg}$. When the systolic and diastolic pressures were in different categories, the higher category was used to classify the person's blood pressure status.

The methods (time of day, subject position, and type of sphygmomanometer) for blood pressure determination were common to both facilities. ${ }^{15} \mathrm{In}$ addition, hypertension in both populations was diagnosed as essential hypertension with no "target organ (diabetes, left ventricular hypertrophy, etc.)" involvement.

\section{Collection of saliva}

Saliva was collected from one parotid gland between the hours of $8 \mathrm{AM}$ to $12 \mathrm{M}$ to minimize the effect of circadian variances. ${ }^{16}$ The Carlson-Crittenden Cup was used to collect saliva. ${ }^{17 .}{ }^{18}$ Subjects did not eat, drink, or perform oral hygiene at least 2 hours before collection. The Stenson's duct was isolated, and the cup positioned over the orifice. Saliva was stimulated for a 2-minute equilibrium period followed by a 2 -minute collection period. A $2 \%$ citric acid solution was applied to the dorsum of the tongue every 30 seconds during the 2-minute equilibrium and 2 -minute collection periods. Samples were collected in preweighed plastic tubes, and salivary output was determined gravimetrically assuming a specific gravity of $1.0 \mathrm{gms} / \mathrm{cm}^{3}$.

\section{Statistical analysis}

The data analysis was performed on an IBM 370 mainframe computer using the SAS Statistical Software Package. ${ }^{19}$ Descriptive analyses were performed on both groups within each separate population. A PROC GLM for unbalanced analysis of variance was used to compare mean levels of stimulated parotid 


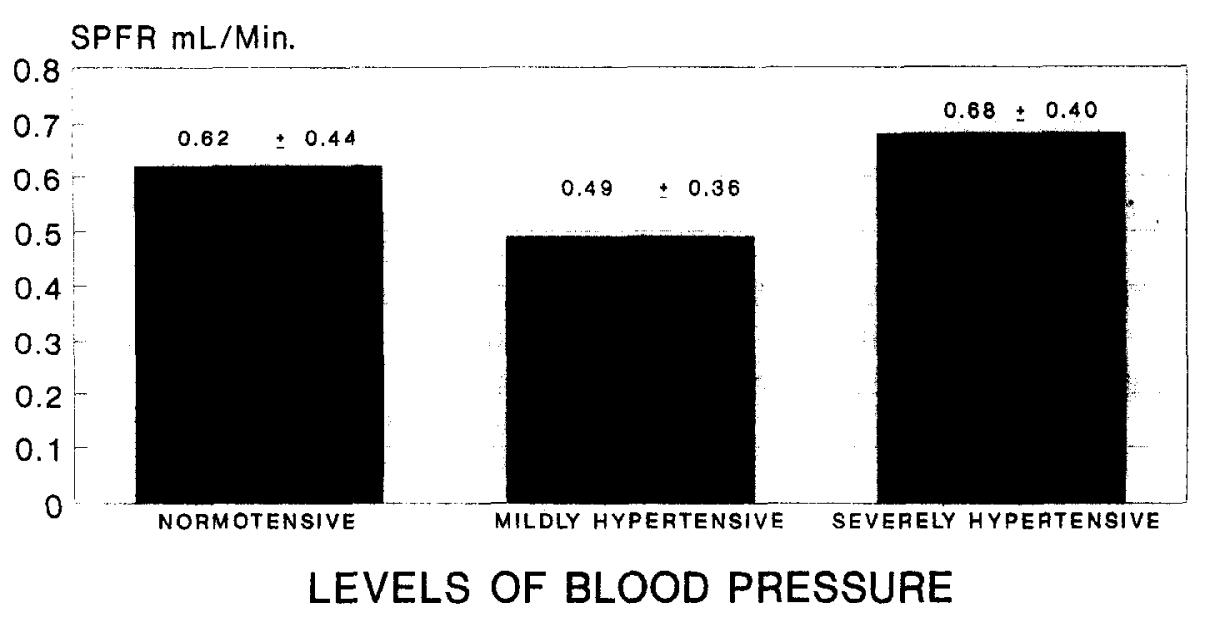

SPFR $\mathrm{mL} / \mathrm{Min}$.

F-ratio $0.70, p=$ not significant

Fig. 1. Stimulated parotid flow rates according to blood pressure status.

Table II. Analysis of variance of population, hypertension status, and hypertension levels for differences in stimulated parotid flow rates

\begin{tabular}{l|c|c|c|c|c}
\hline \multicolumn{1}{c|}{ Source } & Sum of squares & $d f$ & Mean squares & F-value & Probability \\
\hline Overall model & 0.37 & 3 & 0.12 & 0.60 & 0.56 \\
Population & 0.32 & 1 & & 1.83 & 0.18 \\
Hypertension & 0.04 & 1 & & 0.23 & 0.63 \\
Population $\times$ Hypertension & 0.03 & 1 & 0.14 & 0.71 \\
Levels of hypertension & 0.25 & 2 & 0.12 & 0.70 & 0.50 \\
\hline
\end{tabular}

flow rates (SPFR) in milliliters per minute among the four groups of subjects. The models contained two classification variables as main effects: population or site (BLSA versus WVMC representing race) and hypertension status (normotensive versus hypertensive). Because of the small number of women in some of the groups (severe hypertensives), gender differences as a variable were not analyzed. However, in previous studies at the BLSA $^{11,17,21,22}$ and at WVMC, ${ }^{7}$ no gender differences were found in SPFR among either populations.

The data sets were then combined and analysis of variance (PROC GLM) was used to detect differences across three levels of hypertension status, normotensive, mildly hypertensive, and severely hypertensive. $^{19}$ The level of significance referenced for these analyses was $p<0.05$.

\section{RESULTS}

The mean systolic and diastolic blood pressures that placed a person into each blood pressure group are given in Table I. Mean normotensive systolic pressures for the BLSA, WVMC, and the combination of both sites were 120,129 , and 125 , respectively. The mean normotensive diastolic pressures were 67 (BLSA), 86 (WVMC), and 76 (combined data). Systolic pressures for the hypertensive group were 139 for the BLSA and 167 for WVMC. Diastolic pressures for the hypertensive group were 93 for BLSA and 112 for WVMC. In addition, no moderate, severe, or very severe hypertensive persons were found in the BLSA population, and no mildly or very severe hypertensive persons were found in the WVMC population.

Mean SPFR ranged from 0.59 to $0.69 \mathrm{ml} / \mathrm{min}$ for the normotensive subjects (BLSA and WVMC, respectively) whereas the hypertensive SPFR were 0.49 to $0.68 \mathrm{ml} / \mathrm{min}$.

An analysis of variance was performed to determine statistical differences between populations (BLSA, WVMC) and blood pressures (normotensive, hypertensive) with respect to SPFR. The results of the 
analysis of variance showed no significant main effect or interaction with respect to site or hypertension on SPFR (Table II).

Because there were no significant differences in SPFR between the BLSA and WVMC, the normotensive groups in the two sites were combined and an analysis of variance was performed on three levels of blood pressure (Fig. 1). The results of the analysis also showed no significant differences between groups (Table II).

\section{DISCUSSION}

The results of this investigation showed no significant differences in SPFR between normotensive and hypertensive persons. These results parallel the previous study by Niedermeier et al. ${ }^{10}$ that indicated no differences in unstimulated and stimulated whole saliva flow rates between normotensive and hypertensive white and African-American persons. In addition, there have been individual case reports that appear to indicate that SPFR remain the same in both normotensive and hypertensive conditions and that SPFR are not altered until a patient is placed on medication. ${ }^{20}$

A weakness of this study is that it is based solely on cross-sectional analysis, and it has been suggested that it is difficult to determine normal salivary gland flow rates without longitudinal observations. ${ }^{22}$ In addition, normal salivary performance for one person may not necessarily be the same for another under similar medical conditions. ${ }^{22}$ However, the values for SPFR among hypertensive persons do coincide with the range of normal values reported by Ship et al. ${ }^{22}$

Studies that involve untreated hypertensive persons are difficult to implement because of the life-threatening nature of the untreated disease. As a consequence, investigations that demonstrate the iatrogenic effects of antihypertensive medications on salivary function usually consist of medicated persons and nonmedicated controls. Therefore it has been difficult to assess the effects of the disease in its uncontrolled state on salivary function. ${ }^{8}, 14$ Despite the small number of subjects in this investigation, the results suggest that hypertension per se does not cause a diminution of stimulated parotid flow in white and African-American persons. Previous reports of salivary gland dysfunction and xerostomia in hypertensives may more likely be due to specific medications used in the treatment of elevated blood pressure.

By the year 2020, the elderly ( 65 years and older) will comprise nearly $22.3 \%$ of the total population in the United States. ${ }^{23,}{ }^{24}$ Because hypertension is one of the most prevalent diseases in the elderly ${ }^{15}$ and salivary gland function is essential for the maintenance of oral health, ${ }^{2}$ more research is needed concerning the effects of hypertension and its treatment on salivary physiology. This is especially true in AfricanAmerican populations where hypertension is more prevalent.$^{25}$ Studies with larger sample sizes are necessary to further examine the relationships between salivary function and hypertension. In addition, longitudinal studies are necessary to fully assess the sequelae of antihypertensive medications on salivary function. It is to be hoped that medical conditions and treatments, for example, medications, can be identified that have deleterious consequences to oral health and appropriate preventive and treatment protocols instituted to ensure the maintenance of oral functions in all elderly populations.

\section{REFERENCES}

1. Mandel ID. The function of saliva, J Dent Res 1987;66(Special Issue):623-7.

2. Mandel ID. The role of saliva in maintaining oral homeostasis. J Am Dent Assoc 1989;1 19:298-304.

3. Österberg T, Landahl S, Hedegàrd B. Salivary flow, saliva, $\mathrm{Ph}$, and buffering capacity in 70 -year-old men and women. $J$ Oral Rehabil 1984;11:157-70.

4. Sreebny L, Schwartz S. A reference guide to drugs and dry mouth. Gerodontology 1986;5:75-99.

5. Handelman S, Baric J, Saunders R, Espeland M. Hyposalivatory drug induced whole stimulated salivary flow, and mouth dryness in older, long-term care residents. Spec Care Dent 1989;9:12-8.

6. Nederfors T, Twetman S, Dahlof C. Effects of the thiazide diuretic bendroflumethiazide on salivary flow rate and composition. Scand J Dent Res 1989;97:520-7.

7. Streckfus CF, Welsh S, Strahl RC. Pharmacological diminution of secretory IgA in elderly black patients taking antihypertension medications. Oral Surg Oral Med Oral Pathol. 1991;71:50-4.

8. Mattes R, Christensen C., Engelman K. Effects of therapeutic doses of amiloride and hydrochlorothiazide on taste, saliva and salt intake in normotensive adults. Chemical Senses 1988; 13:33-44.

9. Ben-Aryeh H, Schiller M, Shasha S, Szargel R, Gutman D. Salivary composition in patients with essential hypertension and the effect of Pindolol. J Oral Medicine 1981;36:76-8.

10. Niedermeier W, Dreizen S, Stone R, Spies T. Sodium and potassium concentrations in the saliva of normotensive and hypertensive subjects. Oral Surg Oral Med Oral Pathol 1956;9:426-31.

11. Baum BJ. Characteristics of participants in the oral physiology component of the Baltimore longitudinal study of aging. Community Dent Oral Epidemiol 1981;9:128-34.

12. Shock NW, Grevlich RC, Costa PT, et al. Normal human aging: the baltimore longitudinal study of aging, Washington, DC: N.I.H. Publication No. 84-2450, November 1984.

13. Metter EJ, Fleg J, Brant L, Fozard J. Effect of age of entry to a longitudinal study on cross-sectional determination of cardiovascular disease. Aging 1991;3:355-60.

14. Streckfus CF. StrahI RC, Fleek ME, Greene BG. Prevalence of root decay in inner city geriatric patients taking anti-hypertension medications. J Md State Dent Assoc 1985;28:80-1.

15. The 1993 report of the Joint National Committee on detection, evaluation, and treatment of high blood pressure. Washington, DC: U.S. Department of Health and Human Resources, Public Health Services, National Institutes of Health. NIH Publication No. 93-1088, January 1993. 
16. Dawes C. Rhythms in salivary flow rate and composition. Int J Chronobiology 1974;2:253-79.

17. Heft MW, Baum B. Unstimulated and stimulated parotid salivary flow rates in individuals of different ages. J Dent Res 1984;63:1182-5

18. Baum BJ. Characteristics of participants in the oral physiology component of the Baltimore longitudinal study of aging. Community Dent Oral Epidemiol 1981;9:128-34.

19. SAS/STAT User's Guide Version 6, 4th Ed., Vol. 2, Cary, North Carolina: SAS Institute, 1990:898.

20. Streckfus CF, Welsh S, Jenkins P, Miller V, Brown R. The effects of lisinopril and nefedipine on parotid gland function: a preliminary report. J Md State Dent Assoc 1992;35:11-4.

21. Tylenda CA, Ship JA, Fox PC, Baum BJ. Evaluation of submandibular salivary flow rate in different age groups. J Dent Res 1988;67:1225-8.
22. Ship JA, Fox PC, Baum BJ. How much saliva is enough? Normal function defined. J Am Dent Assoc 1991;122:63-9.

23. U.S. Bureau Census Current Populations Report, Projection 18 , Series \#1018, 1989:25.

24. Special report on aging: 1979: Washington, DC: NIH Publication No. 80-1907. February 1980.

25. Saunders E. Cardiovascular diseases in blacks. Philadelphia: F.A. Davis 1991:1-67.

Reprint requests:

Charles F. Streckfus, DDS, MA

EODPP/NIDR/NIH

Westwood Building, Room 718C

5333 Westbard Avenue

Bethesda, MD 20892 